\title{
Knowledge and attitudes related to HIV/AIDS among young adults
}

\author{
Haja Sherief. $S^{1 *}$, Manickavalli.E ${ }^{2}$, Junaid Rahman ${ }^{3}$, Anandhi. ${ }^{4}$ \\ ${ }^{1}$ Associate Professor Department of Pharmacy Practice, Nandha College of Pharmacy, \\ Erode, Tamilnadu, Email: sherief.coll@gmail.com \\ ${ }^{2}$ Assistant Professor Department of Pharmaceutical Chemistry, Nandha College of \\ Pharmacy, Erode, Tamilnadu, Email:manickavallielangovan@gmail.com \\ ${ }^{3}$ Assistant Professor Department of Pharmacology, Nandha College of Pharmacy, \\ Erode, Tamilnadu, Email: junaidrahman@nandhapharmacy.org \\ ${ }^{4}$ Assistant Professor, Department Obstetrics And Gynaecological Nursing , Nandha \\ College of Nursing, Erode, Tamilnadu, Email:Anandhi7272@gmail.com \\ ${ }^{*}$ Corresponding Author
}

\begin{abstract}
This paper starts by thinking about the overwhelming HIV/AIDS hazard factors for youngsters. A mix of precise and account survey was utilized to investigate the different parts of HIV testing as far as approaches, practice and boundaries. This article gives an extensive audit of the accessible writing that is pertinent to HIV/AIDS from three significant points of view. It starts by featuring the worries worldwide about HIV/AIDS and youngsters.
\end{abstract}

Keywords: Young adults, HIV, Knowledge

\section{Introduction}

Youngsters (matured 15-24 years) represent practically $50 \%$ of recently analyzed HIV contaminations. Subsequently, it is especially significant that this segment bunch keeps on being tried and get treatment. Information from the UN are empowering with respect to the decrease in the quantity of new diseases in youngsters. Youngsters' sexual conduct and the connection among this and HIV/AIDS are then talked about. In spite of the fact that danger components and youngsters' practices may represent an immediate danger to their wellbeing status, being youthful is for the most part connected with great wellbeing. Likewise, pubescence is the time that people arrive at sexual development when extra and genuine danger factors for explicitly sent illnesses arise. HIV/AIDS is viewed as associated with examples of unsafe conduct thus it tends to be disposed of, or possibly decreased, by people rolling out proper social improvements to their ways of life. Despite the fact that danger elements and youngsters' practices may represent an immediate danger to their wellbeing status, being youthful is by and large connected with great wellbeing. Social and social qualities could likewise be considered roundabout danger factors for HIV in specific settings. The absence of parent-youngster correspondence concerning sexual issue is an early botched chance for sex instruction, which may add to youths rehearsing dangerous practices early. Absence of proficiency or low degrees of training by and large additionally affect a person's danger of contracting HIV.

\section{Knowledge towards HIV/AIDS in young adults}

Since the beginning of the HIV/AIDS pandemic, there have been numerous missions pointed toward bringing issues to light of dangers and danger decrease measures. Nonetheless, it is fascinating to 44 look at how much the message is getting past and being heard, and to consider people's perspectives and information with respect to HIV/AIDS around the world. attributable to the time allotment that HIV is in brooding, more established youths and youthful grown-ups who tried positive were very likely contaminated while they were more youthful youngsters. This absence of schooling was apparent when the understudies were met albeit a large portion of the understudies focused on that they might want to get familiar with HIV/AIDS. TV and other media were distinguished similar to their primary wellspring of data relating to HIV/AIDS. Be that as it may, a couple of understudies had the option to address the inquiries accurately. The principle mistaken assumptions identified with how people really contract HIV/AIDS, with high rates of understudies wrongly accepting that it very well may be sent by mosquito chomps and by utilizing public pools and public latrines. Additional proof from other Islamic states likewise shows that misguided judgments about transmission are normal. people 
experiencing HIV/AIDS ought not go to 'typical' schools, showing a narrow minded demeanor towards victims predominately through absence of information and comprehension. with the point of investigating the mindfulness, information and thoughts of young adult students corresponding to explicitly communicated diseases and HIV/AIDS. Four evaluate the information on and mentalities towards HIV/AIDS found that the vast majority of the understudies' information about HIV was solid albeit a few confusions actually existed. a very long time after the beginning of HIV/AIDS it isn't just in the creating scene where there remains obliviousness. to attest that the perspectives of more seasoned understudies and female understudies towards individuals living with HIV showed up substantially more sure than those of more youthful understudies and male understudies. The investigation additionally uncovered that understudies' HIV/AIDS related information emphatically connected with their mentalities. The outcomes demonstrated that HIV related information and its connected misinterpretations differed across these nations with a general improvement being found in ongoing overviews. Specifically, the greater part held the accompanying misguided judgments: HIV can't be passed from mother to child; sharing taking care of utensils can send HIV; a revile can make somebody get HIV; and cleaning the privates after sex can keep an individual from contracting HIV. Generally, the current writing here shows an enormous number of comparable misguided judgments across populaces, with little variety by age or sexual orientation. Misguided judgments are by and large impacted by schooling, with advanced education levels expanding information on HIV/AIDS. The writing additionally brought up that the examples of HIV/AIDS misinterpretations were regular across populaces and countries, paying little heed to their scourge status. Nonetheless, there is some help to demonstrate that the degree of shame and segregation appended to HIV/AIDS is related with the degree of HIV/AIDS misguided judgments. An absence of explicit information concerning HIV appears to meddle with the expectation of people to look for testing.

\section{HIV risk in young adults}

It is imperative to analyze the connection between youngsters' practices and HIV/AIDS. sex disparity in agricultural nations demolishes females' capacity to impact or arrange more secure alternatives during sex. The danger taking practices that were assessed, included various sexual accomplices and lifetime sexual accomplices while other non-sexual, hazardous practices were recognized. These included medication use, betting, battling, the utilization of liquor at an early age, burglary, and defacing. Perspectives towards contraception fluctuate significantly and are apparently socially needy; yet while thinking about the predominance of HIV/AIDS, people. The utilization of medications, liquor or other inebriating substances is connected to youths' sexual conduct.

The interaction of HIV testing began not long after the infection was segregated. in vitro considers started to develop the infection and start human testing. there was minimal that should be possible for the individuals who tried positive as antiretroviral drugs were as yet unfamiliar thus the primary reason for treatment was to diminish the spread of the contamination. Following the forward leap of an antiretroviral drug which changed and upgraded the reaction to the pandemic, HIV testing turned into the doorway to improve the personal satisfaction for those tainted with HIV. rules on HIV testing administrations, prescribed ways to deal with such administrations incorporate office and local area based testing, and self-testing; every one of these hug various plans for HIV testing. For instance, an office based methodology incorporates intentional directing and testing administrations, just as supplier started testing and guiding. It should be guaranteed that a person's very own data and HIV sero-status is taken care of with privacy, paying little heed to the setting or the sort of HIV testing administration. The accessibility of fitting guiding is another strand which underpins the basic liberties of a person to get exhortation which should be given in an expert and skilled way. This permits the person to settle on educated decisions identifying with whether he/she needs to be tried for HIV and guarantees that people can quit if routine testing is applied. What's more, the contribution of testing ought to give an affirmation of the "exactness" of the HIV testing result. It is likewise essential to connect the arrangement of testing with the arrangement of conceivable treatment and administrations. This, nonetheless, requires certain degrees of association inside neighborhood wellbeing frameworks with the goal that the necessary treatment administrations are given. Moreover, there is a prerequisite for the medical care association to asset such administrations enough and to oversee them expertly. Dread of being HIV positive, along with its connected undesirable outcomes, seemed, by all accounts, to be the second most basic individual obstruction that was recognized in the examinations surveyed here. Different types of dread were additionally called attention to, for example, dread of derision, dread of social segregation, dread of passing on from AIDS, and dread of an accomplice's response. Likewise, availability to the test additionally appeared to be a test experienced by certain people. Different issues were raised with respect to availability.

\section{Attitude towards HIV}

HIV is a huge issue as testing can demonstrate significant; not exclusively would it be able to help forestall further transmission of the infection, it can likewise assist successful treatment with being given to the victim. The survey of the writing shows that 
setting up what these obstructions are and investigating viable manners by which they can be defeated are of fundamental significant in endeavors both to treat HIV/AIDs and forestall its transmission. Be that as it may, regardless of whether admittance to HIV testing administrations is conceivable on a fundamental level, freedoms to analyze patients are regularly missed, because of real obstructions at different levels. Information from the United Nations are empowering with respect to the diminishing in the quantity of new diseases in youngsters. In any case, UNAIDS and WHO have just featured the need "to tailor counteraction techniques to nearby necessities yet in addition the significance of decentralizing AIDS reactions" (UNAIDS/WHO, 2009). Since there is restricted data about the variables that impact HIV testing practices. quantitative information are gathered first and this is then trailed by the assortment of subjective information. Each strand of the gathered information are then dissected independently. The last end decides if the subjective outcomes have clarified the quantitative outcomes. In the quantitative piece of this work, a graphic crosssectional investigation was directed to recognize the elements that affected HIV testing among college understudies; it additionally analyzed contrasts across the sexes. The subjective piece of the investigation was directed utilizing interviews with medical services experts who represented considerable authority in HIV/AIDS to investigate the boundaries to HIV testing that influenced youngsters.

\section{Conclusion}

In this paper a survey of the current on the issues identified with youthful grown-ups and HIV/AIDS has been talked about, just as HIV testing and the variables that impact HIV testing practices. This was refined through a story review.the deliberate audit zeroed in on distinguishing the elements that affected the take-up of HIV testing among grown-ups around the world. The HIV testing take-up seemed, by all accounts, to be impacted by assortment of elements at various levels however those which identified with a person's mentality, information and discernment about HIV/AIDS appeared to be the most conspicuous. The low degree of HIV hazard insight was the most oftentimes refered to factor that kept people from undertaking the test. At an individual level, the dread of a positive outcome was distinguished as the second most every now and again announced obstruction that added to the low take-up of the HIV test. The social shame appended to HIV/AIDS overall was appeared in the writing to be the main factor at a socio-social level. Shame and segregation appeared to be general components which influenced both creating and created nations. Issues identified with sex disparity and social standards likewise need close consideration, especially in the agricultural countries and those generally genuinely influenced by the scourge. Medical care suppliers additionally confronted difficulties that may add to the low takeup of HIV testing. Different components brought about by the medical services suppliers that were distinguished as conceivably influencing the take-up of testing included medical care suppliers' perspectives. Focusing on clinical intercessions over preventive ones may likewise lessen the usage of HIV testing. Calculated issues, for example, insufficient assets, absence of prepared staff and monetary imperatives, were significant framework or strategy level variables which affected the take-up of HIV testing. In different settings, people are straightforwardly influenced by elements, for example, the inaccessibility of a quick HIV test, the long lines at testing focuses, and the expense of a HIV test. The multifaceted nature of the low take-up of HIV testing, and simultaneously its significance in the battle against HIV/AIDS, were plainly featured in the writing around the world. Exceptionally prepared and asset rich settings, just as helpless asset settings, gave off an impression of being battling in scaling up HIV testing. Considering these issues in picking a methodology that would best satisfy its point presents the methodological and pragmatic techniques just as moral contemplations.

\section{References}

1. Sallar AM. Correlates of misperceptions in HIV knowledge and attitude towards people living with HIV/AIDS (PLHIV) among inschool and out-of-school adolescents in Ghana. Afr Health Sci, 9(2),2009, 82 91.

2. Abruquah HH, Bio FY. HIV/AIDS. Knowledge, attitude and practice of school adolescents in the Kwaebibirem district of Ghana. J Sci Tech,28(2),2008,10-8.

3. Emmanuel G. Regional Youth Forum CEMAC in the fight against HIV, 6th edition HIV cannot pass through the girl (Yaoundé, Cameroon, FREJES VI, 2012)

4. United Nations Children's Fund (UNICEF). Opportunity in Crisis: Preventing HIV from early adolescence to young adulthood (New York, United Nations, 2011).

5. KORBER, B., MULDOON, M., THEILER, J., GAO, F., GUPTA, R., LAPEDES, A., HAHN, B., WOLINSKY, S. \& BHATTACHARYA, T. 2000. Timing the ancestor of the HIV-1 pandemic strains. Science, 288, 1789-1796.

6. HEIJNDERS, M. \& VAN DER MEIJ, S. 2006. The fight against stigma: an overview of stigma-reduction strategies and interventions. Psychology, health \& medicine, 11, 353-363.

7. HONG, Y., ZHANG, C., LI, X. M., FANG, X. Y., LIN, X. Y., ZHOU, Y. J. \& LIU, W. 2012. HIV Testing Behaviors Among Female Sex Workers in Southwest China. Aids and Behavior, 16, 44-52.

8. HOPE, K. W. \& WATERMAN, H. A. 2003. Praiseworthy pragmatism? Validity and action research. Journal of Advanced Nursing, 44, 120-127.

9. HOTTES, T. S., FARRELL, J., BONDYRA, M., HAAG, D., SHOVELLER, J. \& GILBERT, M. 2012. Internet-based HIV and sexually transmitted infection testing in British 
Columbia, Canada: opinions and expectations of prospective clients. Journal of Medical Internet Research, 14, e41-e41.

10. FlOWERS, P., KNUSSEN, C. \& CHURCH, S. 2003.

Psychosocial factors associated with HIV testing among Scottish gay men. Psychology \& Health, 18, 739-752 